\title{
The care continuum in acromegaly: how patients, nurses, and physicians can collaborate for successful treatment experiences
}

This article was published in the following Dove Press journal:

Patient Preference and Adherence

30 July 2015

Number of times this article has been viewed

\author{
Cynthia Plunkett \\ Ariel L Barkan \\ Division of Endocrinology, \\ University of Michigan Medical \\ Center, Ann Arbor, MI, USA
}

Correspondence: Cynthia Plunkett MEND Clinical Research Center, 24 Frank Lloyd Wright, Lobby G/Suite 1500, Ann Arbor, MI 48105, USA

Tel +l 7349368065

Fax + I $734763617 \mid$

Email cplunket@med.umich.edu
Abstract: Patients with acromegaly (a condition of chronic growth hormone hypersecretion by a pituitary adenoma) often require pharmacological treatment. Somatostatin analogs (SSAs) such as pasireotide, lanreotide, and octreotide are frequently used as first-line medical therapy. As SSAs are delivered by regular subcutaneous or intramuscular injections, they can result in injection-related pain or anxiety and can be challenging to fit into patients' lifestyles. When combined with the prolonged, debilitating psychological complications associated with acromegaly, these administration challenges can negatively impact compliance, adherence, and quality of life. Proactively managing patients' expectations and providing appropriate, timely guidance are crucial for maximizing adherence, and ultimately, optimizing the treatment experience. As part of ongoing clinical research since 1997, our team at the University of Michigan has used SSAs to treat 30 patients with acromegaly. Based on our clinical experiences with multiple SSA administration regimens (long-acting intramuscular, long-acting deep subcutaneous, and twicedaily subcutaneous), we generated a dialog map that guides health care professionals through the many sensitive and complex patient communication issues surrounding this treatment process. Beginning with diagnosis, the dialog map includes discussion of treatment options, instruction on proper drug administration technique, and ensuring of appropriate follow-up care. At each step, we provide talking points that address the following: the patients' clinical situation; their geographic, economic, and psychological concerns; and their inclination to communicate with clinicians. We have found that involving patients, nurses, and physicians as equal partners in the treatment process optimizes treatment initiation, adherence, and persistence in acromegaly. By encouraging collaboration across the care continuum, this dialog map can facilitate identification of the treatment plan that is most likely to yield the best possible outcome.

Keywords: somatostatin analogs, pasireotide, octreotide, lanreotide, adherence

\section{Introduction}

Acromegaly is a condition of chronic growth hormone $(\mathrm{GH})$ oversecretion usually due to an underlying pituitary adenoma, which results in excess insulin-like growth factor-1 (IGF-1) secretion predominantly from the liver. Acromegaly is associated with debilitating complications (eg, severe headache, heart disease, cerebrovascular disease, cancer, diabetes mellitus, and kidney failure $)^{1-3}$ that decrease quality of life (QoL $)^{4}$ and increase risk of death. ${ }^{5,6}$ First-line medical treatment generally involves somatostatin analogs (SSAs), which inhibit GH oversecretion by binding to somatostatin receptors in the pituitary adenoma, thereby reducing associated symptoms and comorbidities. ${ }^{7}$ A recent meta-analysis suggested that biochemical control is associated with normalized mortality rates in patients with acromegaly. ${ }^{8}$ However, achieving optimal treatment 
outcomes is often hindered by complications related to patient communication and adherence. ${ }^{9}$

Patients with acromegaly face a variety of difficult challenges. Onset is typically insidious, and as a result, disease diagnosis is often delayed. By the time patients receive appropriate treatment, they may have already endured many years of unexplained symptoms and reduced QoL. While SSAs provide effective biochemical and symptom control for many patients, ${ }^{10}$ they can be challenging to administer (Table 1), and injection-related anxiety or other adverse events can reduce treatment compliance. ${ }^{9,11,12}$ Since 1997, our team at the University of Michigan has used SSAs to treat 30 patients with acromegaly, and we have found that the majority of these issues can be overcome with careful communication across the care continuum. In this paper, we discuss strategies that can be used to optimize health care professional (HCP)-patient communication and to improve the overall treatment experience of patients with acromegaly.

\section{Dialog map}

SSA administration and treatment have been investigated from both a clinical and a patient perspective. ${ }^{13-17}$ Researchers have examined the efficacy and safety of SSA selfadministration, the barriers that impede optimal SSA treatment, and the extent and quality of dialog between patients and HCPs. Results have demonstrated the importance of patient demographics and life situation when considering administration options, and they have suggested that effective HCP-patient communication can promote long-term adherence to SSA medical therapy. We combined these insights with our clinical experiences to generate a dialog

Table I Characteristics of available SSAs indicated for acromegaly

\begin{tabular}{|c|c|c|}
\hline SSA & Formulation & Administration \\
\hline Lanreotide & $\begin{array}{l}\text { Long-acting } \\
\text { depot/autogel }\end{array}$ & $\begin{array}{l}\text { Deep subcutaneous injection every } \\
28 \text { days } \\
\text { Approved for extended dosing } \\
\text { intervals of } 6-8 \text { weeks } \\
\text { Can be administered by self- or } \\
\text { partner injection }\end{array}$ \\
\hline Octreotide & $\begin{array}{l}\text { Long-acting } \\
\text { depot }\end{array}$ & $\begin{array}{l}\text { Intramuscular injection every } 28 \text { days } \\
\text { Administered by a HCP at the clinic } \\
\text { or through a home nurse injection } \\
\text { program }\end{array}$ \\
\hline Pasireotide & $\begin{array}{l}\text { Long-acting } \\
\text { depot }\end{array}$ & $\begin{array}{l}\text { Intramuscular injection every } 28 \text { days } \\
\text { Administered by a HCP at the clinic } \\
\text { or through a home nurse injection } \\
\text { program }\end{array}$ \\
\hline
\end{tabular}

Abbreviations: SSA, somatostatin analog; $\mathrm{HCP}$, health care professional. map, that is, a practical communications guide for HCPs treating acromegalic patients with SSAs.

This dialog map (Figure 1) covers several sensitive nodes in the SSA treatment process: disclosure of the diagnosis, discussion of SSA treatment options, initiation of treatment, and follow-up recommendations. For each therapeutic stage, we present communication strategies, the reasoning behind these strategies, and sample talking points. Although the dialog map focuses specifically on SSA treatment in acromegaly, many of these principles apply broadly to non-SSA acromegaly medical treatments (eg, pegvisomant, an injectable $\mathrm{GH}$ receptor antagonist) and to other chronic diseases that involve injectable medications (eg, type 1 diabetes and multiple sclerosis).

\section{Diagnosis}

Acromegalic patients experience a mixture of emotions upon receiving their diagnosis. ${ }^{17}$ Some of our patients, for example, expressed frustration and anger over delayed diagnosis. Others were exhausted by years of unexplained symptoms and questioned their ability to manage the continuing burden of disease. Some patients were afraid that they had brain cancer, whereas others were relieved that they finally understood what was causing their symptoms. Patients have also expressed feelings of isolation due to the rarity of their condition. As a result of these varied and intense emotional reactions, diagnosis disclosure has been identified as a critical moment for patients with acromegaly. ${ }^{17}$ The diagnosis conversation can set a precedent for future discussions and can also serve to establish a trusting relationship between the patient and physician. ${ }^{18}$

This issue was demonstrated in a recent study that evaluated the dialog between acromegalic patients and their HCPs. ${ }^{17}$ By performing online and in-person interviews with 19 patients, the authors identified diagnosis as a particularly critical moment during the treatment process. Many patients experienced a long path to diagnosis, which resulted in a loss of trust in the medical profession and decreased self-confidence. Notably, the presence of a collaborative relationship between patients and HCPs was highlighted as a particularly important aspect of acromegaly treatment, with authors stating that:

one of the greatest divides in this research was between patients who had found doctors who listened to them, took a more collaborative approach, and were willing to work with them, and patients who had found no such HCPs.

Our approach to diagnosis disclosure involves two key strategies: (1) empathetic listening and (2) provision 


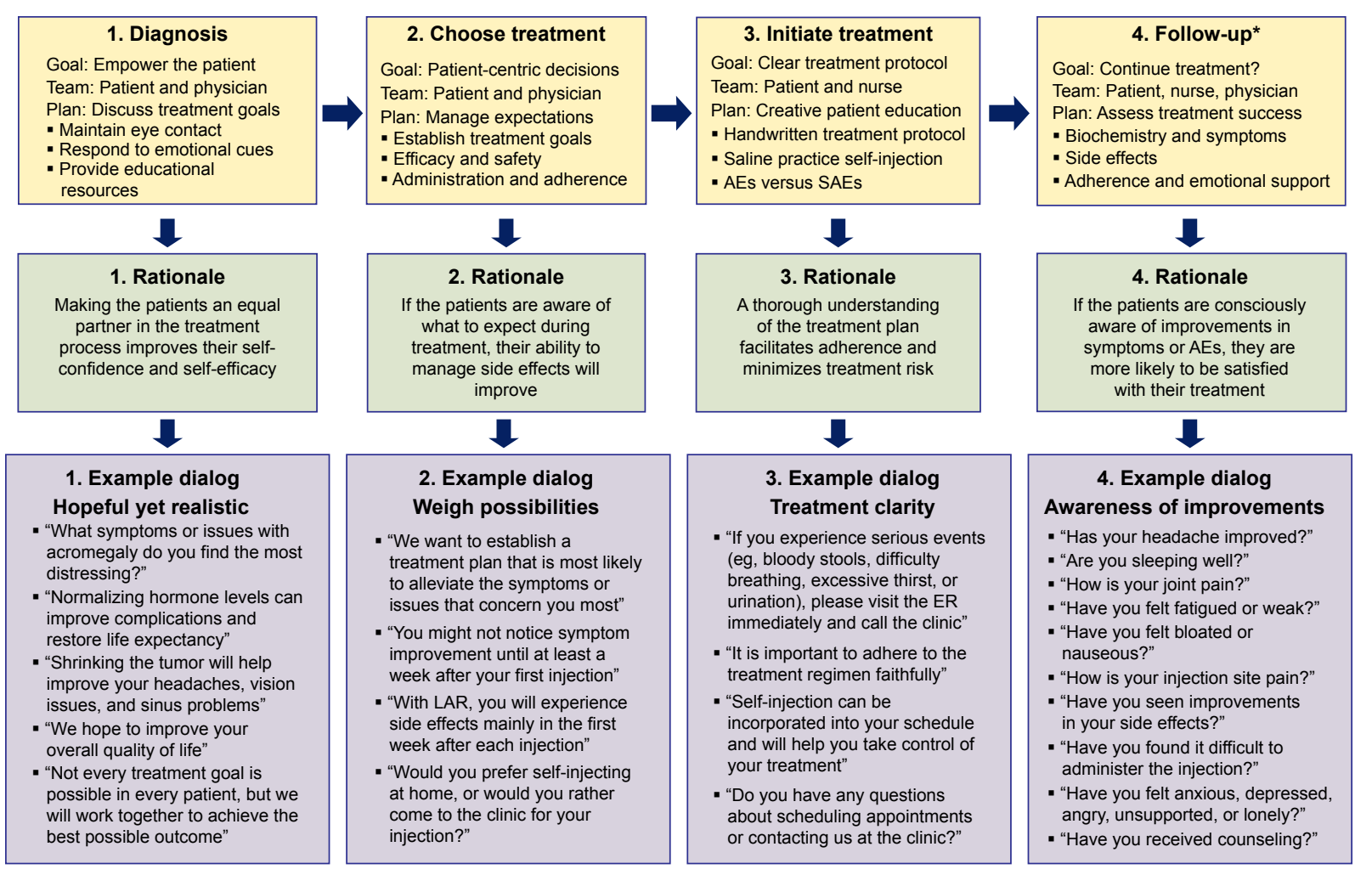

Figure I Dialog map.

Note: *Follow-up should occur every 6 months to I year, depending on laboratory results, symptoms, and AEs.

Abbreviations: AE, adverse event; ER, emergency room; LAR, long-acting release; SAE, serious adverse event.

of educational and emotional resources (Table 2). ${ }^{12,19-22}$ Empathetic listening involves avoiding "provider-centered" communication such as interrupting or lecturing the patient. We recommend asking the patients specific questions about their treatment history and support structure and explicitly encouraging the patients to ask questions themselves. ${ }^{23}$ At this point, it can be helpful to discuss the symptoms or issues with acromegaly that the patient finds most disruptive, which can provide insight into the patient's top treatment priorities. ${ }^{24}$ Patients with acromegaly often develop a strong desire to learn more about their disease ${ }^{17}$ and should be provided with reliable resources. These materials should be understandable and accurate and should temper false expectations while encouraging hope. ${ }^{11}$ For example, it is helpful to communicate that, although acromegaly usually results from a GH-secreting pituitary tumor, it is not a form of brain cancer. Similarly, although acromegaly is associated with debilitating complications and elevated mortality, clinical results suggest that mortality rates, complications, and QoL improve if biochemical control is achieved. ${ }^{4,825-27}$ Table 2 provides a list of useful patient resources, such as links to educational websites and information about peer-topeer support groups. The overarching goal of the diagnosis discussion is to empower the patients so that they become a problem-solving partner in the treatment process. ${ }^{21,28}$

\section{Discussing SSA treatment options}

Assuming that it has been decided that SSA treatment is indicated, the next step in the treatment process involves choosing the appropriate SSA and formulation. This involves addressing a variety of concerns that patients may have about initiating injectable medical therapy. Perhaps owing to a history of ineffective treatments for incorrect diagnoses, acromegalic patients are often concerned about efficacy. After experiencing years of unexplained and uncomfortable symptoms, they are also apprehensive about experiencing side effects. The mode of administration is also of frequent concern. Given that approximately $7 \%-22 \%$ of the general population experiences a form of needle phobia, ${ }^{21}$ many patients will feel uncomfortable at the prospect of selfinjection. In contrast, other patients may be concerned about fitting monthly injections administered at the clinic into their busy lifestyles.

To address these issues, our approach is to ensure that patients have realistic expectations with regard to efficacy and safety. Clinical trial results suggest that lanreotide, octreotide, 
Table 2 Resources for patients with acromegaly

\begin{tabular}{|c|c|}
\hline Purpose & Resource \\
\hline $\begin{array}{l}\text { Administration and } \\
\text { adherence }\end{array}$ & $\begin{array}{l}\text { Automated adherence reminders: emails, } \\
\text { phone calls, letters, and text messages } \\
\text { Mobile administration program: mobile HCPs } \\
\text { deliver long-acting octreotide injections at } \\
\text { home or at a convenient location }\end{array}$ \\
\hline Symptom tracking & $\begin{array}{l}\text { Diary of symptoms, test results, and side } \\
\text { effects } \\
\text { Regular appointment schedule }\end{array}$ \\
\hline $\begin{array}{l}\text { Patient education and } \\
\text { emotional support }\end{array}$ & $\begin{array}{l}\text { Acromegaly Info (www.acromegalyinfo.com) } \\
\text { Hormone Health Network (www.hormone. } \\
\text { org) } \\
\text { Pituitary Disorders (www.pituitarydisorder. } \\
\text { net) } \\
\text { Pituitary Foundation (www.pituitary.org.uk) } \\
\text { Pituitary Society (www.pituitary-society.org) } \\
\text { You and Your Hormones (http://www. } \\
\text { yourhormones.info) } \\
\text { Pituitary Network Association (www.pituitary. } \\
\text { org) } \\
\text { Acromegaly Community (www. } \\
\text { acromegalycommunity.com) } \\
\text { Additional support groups and educational } \\
\text { resources may be found through the endocrine } \\
\text { societies of individual countries/regions }\end{array}$ \\
\hline $\begin{array}{l}\text { Financial resources for } \\
\text { patients without publicly } \\
\text { funded health care }\end{array}$ & $\begin{array}{l}\text { Financial assistance for lanreotide (http:// } \\
\text { acromegaly.somatulinedepot.com/resources/ } \\
\text { copay-savings-programs) } \\
\text { Financial assistance for octreotide and } \\
\text { pasireotide (I-877-LAR-INFO, } \\
\text { www.endocrineaccessnow.com) } \\
\text { Additional financial information may be found } \\
\text { through the endocrine societies of individual } \\
\text { countries/regions }\end{array}$ \\
\hline
\end{tabular}

Abbreviation: HCP, health care professional.

and pasireotide normalize GH and IGF-1 levels in approximately $30 \%-75 \%$ of patients ${ }^{10}$ and reduce tumor volume in up to $80 \%$ of patients in the first year of therapy. ${ }^{29-39} \mathrm{We}$ recommend that physicians communicate that SSAs are helpful but not universally efficacious. Ideally, the physician and patient should work together to identify mutually agreed-upon treatment goals that prioritize the patient's most pressing concerns (eg, improving a particularly disruptive symptom). ${ }^{24}$ It is necessary to discuss how various treatment plans may facilitate achievement of these goals, emphasizing that the patient, physician, and nurse will work together to identify the option that will yield the best possible outcome.

Patients will be better equipped to manage side effects if they are aware of what to expect during treatment. It is therefore important to discuss common adverse events associated with SSAs, including gastrointestinal disorders (diarrhea, nausea, abdominal pain, and vomiting), hyperglycemia and diabetes, elevated liver enzymes, cholelithiasis, headache, and pituitary hormone deficiency. ${ }^{40-42}$ We recommend discussing when these adverse events are likely to occur. For example, with long-acting formulations, patients experience side effects mainly in the first week after each injection; in contrast, with twice-daily subcutaneous injections, transient side effects will likely be experienced every day. Even though adverse events are often experienced with SSAs, patients should be assured that if they experience intolerable adverse events, a new treatment regimen can be considered.

It is critical to discuss administration options before making a final treatment decision. SSA formulations that can be self-administered or administered through home nurse injection programs may be preferable for patients who are selfsufficient, have a busy lifestyle, live far away from the clinic, or are interested in reducing their health care expenses. ${ }^{13,14,16}$ In contrast, monthly injections delivered by a HCP may be ideal for younger patients who are less mature, older patients who are less independent, or patients suffering from needle phobias. ${ }^{43}$ In this manner, patients' age, life history, and current lifestyle affect the choices they make in terms of SSA treatment and may influence how well they adhere to the prescribed medication. Overall, it is important that the patient is an active participant in the treatment discussion. We have found that if treatment decisions are patient-centric, the treatment is more likely to yield successful results.

\section{Initiating treatment}

Initiating SSA treatment can be a challenging time for patients with acromegaly. Patients may lack confidence in their ability to self-inject, or they may worry about injection-related pain. We and others have found that a clear understanding of the treatment plan facilitates adherence and minimizes treatment risk. ${ }^{22}$ Eighteen of our acromegalic patients participated in clinical trials that assessed the efficacy and safety of pasireotide. Although the long-acting, intramuscular formulation of pasireotide was approved for the treatment of acromegaly in 2014, these earlier clinical trials used the subcutaneous formulation of pasireotide, which is self-injected by the patients (or their caregiver) twice daily. To teach our trial participants how to self-inject subcutaneous pasireotide, we created a handwritten, step-by-step procedure for each patient. We then had the patient self-inject saline solution according to his/her individualized protocol. Successfully self-administering subcutaneous saline in the office provided patients with the confidence and independence to self-inject pasireotide at home. We have found that long-term adherence is maximized when the patient and nurse work together to generate an individualized treatment plan; in fact, three of our patients have been successfully selfinjecting pasireotide twice daily for over 9 years. 
A thorough review of SSA safety information is also necessary at treatment initiation. In particular, patients must be able to distinguish an adverse event from a serious adverse event. Serious adverse events associated with SSAs include bloody stools (gastrointestinal dysfunction), rash or difficulty breathing (extreme allergic reaction), or excessive thirst or urination (hyperglycemia). ${ }^{40-42}$ The patient should be advised to visit the emergency room immediately and contact the clinic if any of these symptoms are experienced. It is critical that the patient can readily distinguish between uncomfortable side effects, adverse effects that should be discussed at the next clinical visit, and serious adverse events that require immediate medical attention. If the patient knows exactly what to do if a serious adverse event is experienced, treatment risk associated with SSAs can be minimized.

\section{Follow-up}

Clinical research has indicated that persistence is challenging for patients with chronic diseases. Poor compliance is expected in $30 \%-50 \%$ of all patients regardless of diagnosis, ${ }^{44}$ and a meta-analysis of 569 studies identified an average nonadherence rate of $24.8 \%$ in patients with a range of chronic illnesses. ${ }^{45} \mathrm{~A}$ variety of factors can contribute to nonadherence (Table 3). ${ }^{11,18,46-50}$ While HCPs tend to view adherence with singular focus (biochemical and symptom control), patients balance their treatment against the complexities of everyday life, including the occurrence of major events (eg, marriage, divorce, pregnancy), travel requirements, lack of emotional support, forgetfulness, or development of acute or other chronic illness. ${ }^{12,21,51}$ Adherence is further complicated by the fact that these issues do not exist in isolation; for example, the ability to recall information can be negatively influenced by stress, ${ }^{19,52}$ and patients who are depressed may be more likely

Table 3 Factors that can impede or promote adherence to chronic medical therapy

\begin{tabular}{ll}
\hline Adherence barriers & Adherence promoters \\
\hline Forgetting to take medication & Automated reminders to take \\
Anxiety (eg, needle phobia) & medication \\
Lack of family support & Self-efficacy \\
Perceived lack of efficacy & Family support \\
Coping with adverse events & Satisfaction with current treatment \\
Depression & Keeping a symptom diary \\
Treatment fatigue & Seeing improvements in symptoms \\
Life disruptions & Rewarding oneself after injections \\
Financial concerns & Availability of peer-to-peer patient \\
Perceived lack of HCP support & support \\
Lack of emotional self-sufficiency & Inspiring other patients \\
& Perceived HCP support \\
& Patient's understanding of the \\
\hline
\end{tabular}

Abbreviation: $\mathrm{HCP}$, health care professional. to experience injection-related pain. ${ }^{53}$ It is also important to consider that not every issue applies to each patient, and that treatment challenges change as the patient's life evolves. Identifying and addressing barriers to adherence, therefore, require careful communication throughout the treatment process.

With acromegaly, successful, long-term treatment with SSAs requires that the patient, nurse, and physician effectively manage many barriers to optimal adherence and persistence. These can include the belief that treatment is ineffective (eg, symptomatology despite biochemical control) or the occurrence of ongoing, uncomfortable side effects. Conversely, a recent pilot study indicated that medical treatment was sometimes discontinued in acromegalic patients with active disease but no symptoms, or with mild symptoms that did not obviously improve with therapy. ${ }^{15}$ These issues should be addressed by ensuring that each patient is consciously aware of improvements in his/her clinical condition. To do this, we recommend asking the patients specific questions about their symptoms and side effects at every visit (Figure 1 provides examples). In particular, it is necessary to ensure that the patient can distinguish symptoms that can be improved once biochemistry is controlled (eg, soft tissue inflammation) from those that cannot (eg, irreversible bone growth). Adverse event management techniques should be reviewed, and the patient should be encouraged to keep a diary of ongoing symptoms and side effects. ${ }^{11,18}$ If patients are regularly and carefully keeping track of their treatment experience, they are more likely to be aware that their treatment is working, which results in increased treatment satisfaction and improved adherence. ${ }^{12}$

Adherence and persistence can also be impaired by a challenging administration regimen ${ }^{48}$ If the patients find it difficult to take time off work to visit the clinic for their monthly injection, it may be necessary to evaluate an option that can be self-administered at home or through home nurse injection programs. It may also be possible to increase the interval between injections, as lanreotide is approved for extended dosing periods of 6-8 weeks (Table 1) ${ }^{40}$ If the patient's self-injection technique appears to have lapsed (eg, the presence of lumps, bumps, or bruises), it is necessary to review the self-injection protocol and ensure that the patient is rotating his/her injection sites. If a patient is experiencing burning at the injection site with intramuscular octreotide, switching to a subcutaneous SSA should be considered, as subcutaneous administration has been described as less painful. ${ }^{14}$ The use of techniques that are motivational (eg, rewarding oneself after each injection) or memory inducing (eg, using automated treatment reminders) should be encouraged, as these have been reported to increase adherence in chronic conditions (Table 2). ${ }^{11,18,49}$ 
We believe that if problems are identified early, they can be addressed before they become insurmountable barriers to medical therapy. We recommend that the physician, nurse, and patient meet every 6 months to 1 year to discuss the biochemical, clinical, practical, and emotional aspects of SSA treatment. If biochemical results or symptoms indicate a lack of efficacy and/or if adverse events are intolerable, it may be necessary to discuss changing treatment. These regular visits ensure that the goals of all members of the treatment team are aligned as the patient's life evolves.

\section{Conclusion}

Acromegaly is associated with a considerable burden of disease. Diagnosis is often substantially delayed, patients experience debilitating physical and emotional complications, and many acromegaly medications are associated with challenging administration regimens and potential side effects. Improving the QoL of patients with this debilitating disorder is of paramount importance. Strategic communication can facilitate adherence and persistence to challenging treatment regimens; however, development of simpler administration devices or new SSA formulations (eg, orally delivered SSAs) could be enormously beneficial. ${ }^{54}$ Given the many challenges associated with current SSA formulations, we believe that future research in acromegaly treatment should focus on the development of more manageable administration options.

In the meantime, however, we have found that treatment experience can be improved with effective communication across the care continuum. The presented dialog map, which includes strategies developed in our clinical practice, can be used to encourage patient-centric treatment decisions, to communicate realistic treatment expectations, to generate individualized treatment plans, to promote symptom and adverse event awareness, and to provide emotional support. By using these communication strategies, the physician, nurse, and patient can work together to identify the treatment plan that will lead to the best possible outcome.

\section{Acknowledgments}

Financial support for medical editorial and administrative support was provided by Novartis Pharmaceuticals Corporation, East Hanover, NH, USA. The authors thank Joanna Rowell, PhD (Mudskipper Inc), for medical editorial assistance with this manuscript.

\section{Disclosure}

ALB served as an investigator for Novartis and as an advisory board member for Genentech, Ipsen, and Novartis. CP has no conflicts of interest to disclose in this work.

\section{References}

1. Auriemma RS, Galdiero M, De Martino MC, et al. The kidney in acromegaly: renal structure and function in patients with acromegaly during active disease and 1 year after disease remission. Eur J Endocrinol. 2010; 162(6): 1035-1042.

2. Colao A, Pivonello R, Grasso LF, et al. Determinants of cardiac disease in newly diagnosed patients with acromegaly: results of a 10 year survey study. Eur J Endocrinol. 2011;165(5):713-721.

3. Melmed S, Casanueva FF, Klibanski A, et al. A consensus on the diagnosis and treatment of acromegaly complications. Pituitary. 2013; 16(3):294-302.

4. Ben-Shlomo A, Sheppard MC, Stephens JM, Pulgar S, Melmed S. Clinical, quality of life, and economic value of acromegaly disease control. Pituitary. 2011;14(3):284-294.

5. Holdaway IM, Rajasoorya RC, Gamble GD. Factors influencing mortality in acromegaly. J Clin Endocrinol Metab. 2004;89(2):667-674.

6. Dekkers OM, Biermasz NR, Pereira AM, Romijn JA, Vandenbroucke JP. Mortality in acromegaly: a metaanalysis. J Clin Endocrinol Metab. 2008; 93(1):61-67.

7. Sherlock M, Woods C, Sheppard MC. Medical therapy in acromegaly. Nat Rev Endocrinol. 2011;7(5):291-300.

8. Holdaway IM, Bolland MJ, Gamble GD. A meta-analysis of the effect of lowering serum levels of GH and IGF-I on mortality in acromegaly. Eur J Endocrinol. 2008;159(2):89-95.

9. Adelman DT, Liebert KJ, Nachtigall LB, Lamerson M, Bakker B. Acromegaly: the disease, its impact on patients, and managing the burden of long-term treatment. Int J Gen Med. 2013;6:31-38.

10. Carmichael JD, Bonert VS, Nuño M, Ly D, Melmed S. Acromegaly clinical trial methodology impact on reported biochemical efficacy rates of somatostatin receptor ligand treatments - a meta-analysis. J Clin Endocrinol Metab. 2014;99(5):1825-1833.

11. Costello K, Kennedy P, Scanzillo J. Recognizing nonadherence in patients with multiple sclerosis and maintaining treatment adherence in the long term. Medscape J Med. 2008;10(9):225.

12. Pyatak EA, Florindez D, Weigensberg MJ. Adherence decision making in the everyday lives of emerging adults with type 1 diabetes. Patient Prefer Adherence. 2013;7:709-718.

13. Bevan JS, Newell-Price J, Wass JA, et al. Home administration of lanreotide Autoge $\mathrm{l}^{\circledR}$ by patients with acromegaly, or their partners, is safe and effective. Clin Endocrinol (Oxf). 2008;68(3):343-349.

14. Salvatori R, Nachtigall LB, Cook DM, et al; SALSA Study Group. Effectiveness of self- or partner-administration of an extended-release aqueous-gel formulation of lanreotide in lanreotide-naive patients with acromegaly. Pituitary. 2010;13(2):115-122.

15. Kasuki L, Marques NV, Nuez MJ, Leal VL, Chinen RN, Gadelha MR. Acromegalic patients lost to follow-up: a pilot study. Pituitary. 2013;16(2):245-250.

16. Salvatori R, Woodmansee WW, Molitch M, Gordon MB, Lomax KG. Lanreotide extended-release aqueous-gel formulation, injected by patient, partner or healthcare provider in patients with acromegaly in the United States: 1-year data from the SODA registry. Pituitary. 2014; 17(1):13-21.

17. Gurel MH, Bruening PR, Rhodes C, Lomax KG. Patient perspectives on the impact of acromegaly: results from individual and group interviews. Patient Prefer Adherence. 2014;8:53-62.

18. Smrtka J, Caon C, Saunders C, Becker BL, Baxter N. Enhancing adherence through education. J Neurosci Nurs. 2010;42(5 suppl):S19-S29.

19. Linn AJ, van Weert JC, Schouten BC, Smit EG, van Bodegraven AA, van DL. Words that make pills easier to swallow: a communication typology to address practical and perceptual barriers to medication intake behavior. Patient Prefer Adherence. 2012;6:871-885.

20. White CP, White M, Russell CS. Multiple sclerosis patients talking with healthcare providers about emotions. JNeurosci Nurs. 2007;39(2): 89-101.

21. Saunders C, Caon C, Smrtka J, Shoemaker J. Factors that influence adherence and strategies to maintain adherence to injected therapies for patients with multiple sclerosis. J Neurosci Nurs. 2010;42(5 suppl): S10-S18. 
22. Martin LR, Williams SL, Haskard KB, Dimatteo MR. The challenge of patient adherence. Ther Clin Risk Manag. 2005;1(3):189-199.

23. Brown RF, Butow PN, Dunn SM, Tattersall MH. Promoting patient participation and shortening cancer consultations: a randomised trial. Br J Cancer. 2001;85(9):1273-1279.

24. Grant RW, Adams AS, Bayliss EA, Heisler M. Establishing visit priorities for complex patients: a summary of the literature and conceptual model to guide innovative interventions. Healthcare (Amst). 2013;1(3-4):117-122.

25. Colao A, Cannavò S, Marzullo $\mathrm{P}$, et al. Twelve months of treatment with octreotide-LAR reduces joint thickness in acromegaly. Eur $J$ Endocrinol. 2003;148(1):31-38.

26. Colao A, Marzullo P, Ferone D, et al. Cardiovascular effects of depot long-acting somatostatin analog Sandostatin LAR in acromegaly. J Clin Endocrinol Metab. 2000;85(9):3132-3140.

27. Colao A, Terzolo M, Bondanelli M, et al. GH and IGF-I excess control contributes to blood pressure control: results of an observational, retrospective, multicentre study in 105 hypertensive acromegalic patients on hypertensive treatment. Clin Endocrinol (Oxf). 2008;69(4):613-620.

28. Wagner EH, Austin BT, Von Korff M. Organizing care for patients with chronic illness. The Milbank Quarterly. Vol 74. Hoboken, NJ: Wiley; 1996:511-544.

29. Colao A, Ferone D, Marzullo P, et al. Long-term effects of depot longacting somatostatin analog octreotide on hormone levels and tumor mass in acromegaly. J Clin Endocrinol Metab. 2001;86(6):2779-2786.

30. Colao A, Pivonello R, Rosato F, et al. First-line octreotide-LAR therapy induces tumor shrinkage and controls hormone excess in patients with acromegaly: results from an open, prospective, multicentre trial. Clin Endocrinol (Oxf). 2006;64(3):342-351.

31. Colao A, Pivonello R, Auriemma RS, et al. Predictors of tumor shrinkage after primary therapy with somatostatin analogues in acromegaly: a prospective study in 99 patients. J Clin Endocrinol Metab. 2006;91(6):2112-2118.

32. Ronchi CL, Boschetti M, Degli Uberti EC, et al; Italian Multicenter Autogel Study Group in Acromegaly. Efficacy of a slow-release formulation of lanreotide (Autogel $120 \mathrm{mg}$ ) in patients with acromegaly previously treated with octreotide long acting release (LAR): an open, multicentre longitudinal study. Clin Endocrinol (Oxf). 2007;67(4):512-519

33. Colao A, Pivonello R, Auriemma RS, et al. Growth hormone-secreting tumor shrinkage after 3 months of octreotide-LAR therapy predicts the response at 12 months. J Clin Endocrinol Metab. 2008;93(9): 3436-3442.

34. Attanasio R, Lanzi R, Losa M, et al. Effects of lanreotide Autogel on growth hormone, insulinlike growth factor 1, and tumor size in acromegaly: a 1-year prospective multicenter study. Endocr Pract. 2008;14(7): 846-855.

35. Colao A, Auriemma RS, Rebora A, et al. Significant tumour shrinkage after 12 months of Lanreotide Autogel-120 mg treatment given first-line in acromegaly. Clin Endocrinol (Oxf). 2009;71(2):237-245.

36. Colao A, Bronstein MD, Freda P, et al; Pasireotide C2305 Study Group. Pasireotide versus octreotide in acromegaly: a head-to-head superiority study. J Clin Endocrinol Metab. 2014;99(3):791-799.
37. Bruns C, Lewis I, Briner U, Meno-Tetang G, Weckbecker G. SOM230: a novel somatostatin peptidomimetic with broad somatotropin release inhibiting factor (SRIF) receptor binding and a unique antisecretory profile. Eur J Endocrinol. 2002;146(5):707-716.

38. Ben-Shlomo A, Melmed S. Pasireotide - a somatostatin analog for the potential treatment of acromegaly, neuroendocrine tumors and Cushing's disease. IDrugs. 2007;10(12):885-895.

39. Grasso LF, Pivonello R, Colao A. Investigational therapies for acromegaly. Expert Opin Investig Drugs. 2013;22(8):955-963.

40. Carmichael JD. Lanreotide depot deep subcutaneous injection: a new method of delivery and its associated benefits. Patient Prefer Adherence. 2012;6:73-82.

41. Novartis Pharmaceuticals Corporation. Sandostatin LAR ${ }^{\circledR}$ Depot (Octreotide Acetate for Injectable Suspension); 2011.

42. Novartis Pharmaceuticals Corporation. Signifor Prescribing Information; 2012. Available from: http://www.pharma.us.novartis.com/cs, www.pharma.us.novartis.com/product/pi/pdf/signifor.pdf

43. Cox D, Stone J. Managing self-injection difficulties in patients with relapsing-remitting multiple sclerosis. J Neurosci Nurs. 2006;38(3): 167-171.

44. Vermeire E, Hearnshaw H, Van RP, Denekens J. Patient adherence to treatment: three decades of research. A comprehensive review. J Clin Pharm Ther. 2001;26(5):331-342.

45. Dimatteo MR. Variations in patients' adherence to medical recommendations: a quantitative review of 50 years of research. Med Care. 2004;42(3):200-209.

46. Fraser C, Hadjimichael O, Vollmer T. Predictors of adherence to Copaxone therapy in individuals with relapsing-remitting multiple sclerosis. J Neurosci Nurs. 2001;33(5):231-239.

47. Fraser C, Hadjimichael O, Vollmer T. Predictors of adherence to glatiramer acetate therapy in individuals with self-reported progressive forms of multiple sclerosis. J Neurosci Nurs. 2003;35(3):163-170.

48. Osterberg L, Blaschke T. Adherence to medication. N Engl J Med. 2005; 353(5):487-497.

49. Turner AP, Kivlahan DR, Sloan AP, Haselkorn JK. Predicting ongoing adherence to disease modifying therapies in multiple sclerosis: utility of the health beliefs model. Mult Scler. 2007;13(9):1146-1152.

50. Zolnierek KB, Dimatteo MR. Physician communication and patient adherence to treatment: a meta-analysis. Med Care. 2009;47(8): 826-834.

51. Hortensius J, Kars MC, Wierenga WS, Kleefstra N, Bilo HJ, van der Bijl JJ. Perspectives of patients with type 1 or insulin-treated type 2 diabetes on self-monitoring of blood glucose: a qualitative study. $B M C$ Public Health. 2012;12:167.

52. Kessels RP. Patients' memory for medical information. $J R$ Soc Med. 2003;96(5):219-222.

53. Kalia LV, O'Connor PW. Severity of chronic pain and its relationship to quality of life in multiple sclerosis. Mult Scler. 2005;11(3):322-327.

54. Stormann S, Schopohl J. Emerging drugs for acromegaly. Expert Opin Emerg Drugs. 2014;19(1):79-97.
Patient Preference and Adherence

\section{Publish your work in this journal}

Patient Preference and Adherence is an international, peer-reviewed, open access journal that focuses on the growing importance of patient preference and adherence throughout the therapeutic continuum. Patient satisfaction, acceptability, quality of life, compliance, persistence and their role in developing new therapeutic modalities and compounds to optimize

\section{Dovepress}

clinical outcomes for existing disease states are major areas of interest for the journal. This journal has been accepted for indexing on PubMed Central. The manuscript management system is completely online and includes a very quick and fair peer-review system, which is all easy to use. Visit http://www. dovepress.com/testimonials.php to read real quotes from published authors. 